\title{
Biblioteca e educação em interlocução: repatriar luz/esperança
}

\begin{abstract}
Alcenir Soares dos Reis
\end{abstract}
Doutora em Educação. Professora Associada da Escola de Ciência da Informação da UFMG

http://dx.doi.org/10.1590/1981-5344/2287

Discute-se a relação biblioteca e educação e aponta-se que a interlocução entre as instituições ainda não se realiza da forma proposta no nível do discurso. Destacase que apesar do reconhecimento da necessidade dessa interação a situação paradoxal permanece, ou seja, bibliotecários e professores ainda atuam separadamente. Argumenta-se sobre a identidade educativa presente nas duas funções, considerando que o cerne de ambas é a dimensão informacional. Aponta a relevância dos processos reflexivos como elemento importante para orientar a ação. Propõe-se o repensar da atuação dos profissionais, através da conjugação de uma perspectiva utópica, da competência e do compromisso profissional. Advoga a relevância de que a juventude participe dos bens culturais como mecanismo de esperança e cidadania. Indicam-se algumas possibilidades de concretizar a interlocução biblioteca e educação e defende-se, a importância de viabilizar a tríade informação, conhecimento e imaginação.

Palavras-chave: Interação biblioteca-educação. Processo educativo. Dimensão informacional.

\section{Library and Education in dialogue: repatriate light/hope}

It is discussed the relationship "Library and Education" and it is pointed out that the dialogue between these institutions is not yet performed in the way proposed by the discourse. It is noteworthy that despite the recognition of the necessity of this interaction it remains a paradoxical situation, in other words librarians and teachers still act separately. We argue about the 
educational identity present in this two functions, considering that the core of both is the informational dimension. It is pointed out the relevance of reflective processes as an important element for guiding the action. It is proposed to rethink the role of professionals, through the combination of a utopian perspective, competence and professional commitment. It defends the importance that youth should participate in the cultural assets as a mechanism of hope and citizenship. It presents a number of possibilities to realize the dialogue between library and education and it defends the importance of making the triad information, knowledge and imagination.

Keywords: Interaction library-education. Educational process. Informational dimension.

Recebido em26.11.2014 Aceito em 27.11.2014

\section{Introdução}

Repatriar a luz pros olhos da mocidade

Pros que fizeram jus, pros que ainda hão de fazer

(Quero falar de amor) ${ }^{1}$

Minha escola primária...

Eu era um casulo feio, informe e inexpressivo

Ela me refez, me desencantou

Abriu pela paciência e didática da velha mestra,

Cinquentanos mais do que eu, o meu

Entendimento

Ocluso.

${\text { (Mestra Silvina })^{2}}^{2}$

1 Música de Ivan Lins, Vitor Martins e Ivano Fosseti. Álbum Amorágio. Disponível em: <https://itunes.apple.com/br/album/amoragio/id538911454>. Acesso em: 12 fev. 2014. 
A proposta deste texto é apresentar, tendo por referência a exposição oral efetuada no Seminário "A biblioteca pública no século XXI: lugar social, atuação política e estratégias de mobilização cultural", as reflexões que nortearam os pontos corporificados no debate, notadamente em relação ao significado e a importância das bibliotecas no contexto contemporâneo sem se ater, no entanto, as suas diferentes tipologias pública, escolar, universitária - visando apontar os desafios em termos de sua função social e política.

Vale ressaltar, porém que, no presente texto consideramos oportuno, após resgatar os elementos apresentados no Seminário, promover uma análise da relação entre biblioteca e educação, visando demonstrar suas interconexões. Para fazê-lo, tomamos como centralidade a função educativa das bibliotecas públicas, evidenciando, porém, a singularidade dos seus fazeres enquanto elementos relevantes para a dimensão formativa dos agentes sociais.

É relevante apontar que a distinção e a especificidade de cada uma das instituições

- Escola e Biblioteca - não devem ser visualizadas como decorrência de relações de dicotomia, mas, significa, de maneira fundamental, a exigência de um olhar atento, haja vista a necessidade de compreendê-las de forma global e no âmbito de suas especificidades, tendo-se em vista a complexidade desta interação.

Em razão dos aspectos acima explicitados e considerando as preocupações que nos levaram a esse debate temático, o presente texto organiza-se indicando os antecedentes motivadores para o Seminário e em seguida, promove-se uma análise das interconexões bibliotecaeducação.

\section{Motivadores do Seminário}

Tendo em vista a preocupação de discutir a problemática da biblioteca pública e sua importância social e política no século XXI, além de pensar suas possibilidades de mobilização social, optamos por organizar o Seminário de forma a privilegiar as discussões destas temáticas. Para tal, contamos com 0 aporte de pesquisadores preocupados com as reflexões relativas à biblioteca pública e que apresentaram distintos argumentos e pontos de vista, resultando em um amplo painel das questões que perpassam tal instituição. Estas contribuições evidenciaram, de forma destacada, a pertinência das discussões, bem como a necessidade de prosseguir no debate e nas reflexões teóricas sobre o tema.

Somando-se aos aspectos acima apontados, merece colocar em pauta que o recorte dado ao Seminário teve por intuito compreender a relevância da biblioteca pública no contexto da sociedade brasileira, pensando-a como instrumento importante para a formação do leitor, à

2 Poema de Cora Coralina. In: Melhores poemas Cora Coralina. Seleção de Darcy França Denófrio. São Paulo: Global, 2004. 
promoção dos direitos de cidadania e, ainda, como elemento dinamizador dos processos educativos. Aliados a estes aspectos tivemos como elemento motivador a crença que, à medida que a biblioteca amplie seu espaço de intervenção social, agregando os sujeitos de diferentes lugares sociais e exercendo de forma plena seu caráter mobilizador, tornar-se-á possível viabilizar ações mais efetivas que possam contribuir para os processos de mudança necessários à sociedade brasileira.

Assim, explicitado os recortes definidos para este texto, apresentase a seguir as reflexões centradas em torno da relação bibliotecaeducação.

\section{Biblioteca e educação: indagações?}

Se tomarmos como referência diferentes análises teóricas relativas à biblioteconomia e à educação, torna-se possível identificar uma permanente preocupação com a importância da interação entre essas áreas, bem como a compreensão da necessidade de haver uma relação de interdependência e complementaridade nas ações que estas instituições Biblioteca e Educação - devem realizar.

Porém, se no plano do discurso é inegável tal reconhecimento, o processo de tornar viável a proposta de interação entre as áreas, em instrumento de ação, apresenta-se de forma sistemática, atravessada por inúmeras dificuldades. Sob uma perspectiva crítica, detectamos que elas se situam no âmbito da formação destes profissionais, na questão estrutural ligada aos limites institucionais presentes no contexto da educação e da biblioteca, nas condições de infraestrutura nas quais as duas instituições efetivam suas práticas, bem como a longa situação histórica e cultural brasileira.

Conforme apontam as análises da educação e da cultura, é patente que, no caso brasileiro, a opção foi sempre de privilegiar as elites, instaurando-se e mantendo-se um processo de exclusão da população de tais benefícios, fato que se faz presente ao longo da história. Esta realidade hoje se evidencia, haja vista a importância de se colocar em destaque a necessidade de uma efetiva política para a educação de jovens e adultos frente ao número de pessoas analfabetas no contexto da realidade nacional.

Tomando o ponto de vista dos bibliotecários como elemento de análise, verificamos que os argumentos apresentados enfatizam a relevância da atuação dos mesmos no processo pedagógico, nas múltiplas possibilidades presentes na biblioteca, nas potencialidades do acervo, tanto quanto na centralidade e nas infinitas alternativas de acesso às informações propiciadas pelas tecnologias, razão pela qual os bibliotecários colocam em relevo, como marca de seu trabalho atual a função de "mediador da informação".

Entretanto, é preciso demarcar, a partir de nossa compreensão, que "mediador da informação", assinalado como a nova postulação identificadora da atuação do profissional bibliotecário, não pode ser compreendida apenas em sua dimensão de operacionalidade, uma das 
vertentes sob as quais vem sendo apresentada. Na realidade, o papel do bibliotecário deve ser compreendido como a de um ator privilegiado na interação entre o usuário e o conhecimento, negando-se, portanto, o estereótipo de compreendê-lo sob o prisma de uma atividade mecânica, ou de apenas "meio", haja vista que a função de mediação requer dinamizar as potencialidades desta interação tendo como perspectiva a possibilidade de ampliar o campo de compreensão do real.

Nestes termos, vale explicitar o conceito de mediação advindo do trabalho de pesquisa e formulado por Martins (2009), cuja sistematização apresenta-se consolidada no artigo de Reis e Martins (2009), a partir da qual se define mediação nos seguintes termos: "[...] entendemos a mediação informacional como um processo a partir do qual os atores em inter-relação, situados em campos histórico-culturais de conflito e contradição, negociam, disputam e confrontam sentidos simbólicos destinados à leitura, apreensão e nomeação do real".

Porém, se há para o profissional bibliotecário as considerações acima, vale recuperar os elementos da discussão, fundamentalmente em relação à dimensão de interação entre os profissionais, agora, a partir da perspectiva dos educadores.

Assim, retomando a análise da relação biblioteca-educação a partir do ponto de vista dos educadores, vamos detectar um discurso semelhante ao dos bibliotecários no qual se destacam às afirmativas de positividade quanto à importância da biblioteca no processo pedagógico, as necessidades de interação entre educadores e bibliotecários e a oportunidade de avanço na construção do conhecimento.

Somados a estas, há ainda o reconhecimento de que o resultado desta interação - o acesso à informação e à pesquisa propiciada pela biblioteca - se traduziria, em termos concretos na formação dos sujeitos, em possibilidades de independência intelectual, na capacidade de discernimento e na crítica em relação à realidade, elementos que seguramente deverão permitir uma atuação cidadã no contexto da realidade nacional.

Entretanto, quando analisamos estas formulações, buscando captar os elementos subjacentes aos discursos dos profissionais, torna-se evidente que, apesar do reconhecimento desta importância e das críticas à ausência de uma pertinente integração entre educadores e bibliotecários, tal situação dissonante permanece, o que mostra sua dimensão paradoxal.

Porém, é preciso reconhecer que há exceções e que esta visão ora apresentada concretamente, por vezes se nega para a totalidade das relações entre bibliotecários e educadores. Há importantes trabalhos desenvolvidos entre os mesmos, em projetos e ações convergentes, que têm como foco o processo de ensino aprendizagem e o avanço na educação, ao lado do reconhecimento da Biblioteca e de seus profissionais como um fator importante para o contexto pedagógico.

Tal reconhecimento, porém, não suprime a importância de se discutir a necessidade de fortalecer esta relação e incluir na pauta dos problemas atinentes aos bibliotecários e aos educadores a preocupação de 
sair da dimensão da constatação e de crítica, e caminhar na direção de uma ação mais efetiva e dinâmica, buscando a inversão desta realidade.

Penso ser oportuno incorporar uma formulação de Gadotti (1981), apresentada em exposição oral, enquanto um dos participantes do debate sobre a função da Universidade, segundo a qual "criticar muito é pouco; temos que passar da crítica à proposta". ${ }^{3}$ Creio então que os aspectos contraditórios que perpassam as relações entre bibliotecários e educadores devem, seguramente, ser explicados para além das interações entre estes profissionais, incorporando-se, neste sentido, às múltiplas dimensões históricas, políticas e culturais da sociedade brasileira. Tornase necessário, ainda, avançar e não abrir mão da crítica, mas colocar no horizonte as estratégias de ação. Entretanto, antes de se explicitar as potencialidades da relação biblioteca-educação, considera-se oportuno lançarmos mão de dois pontos importantes para nortear esta discussão no que se refere à interação entre as áreas.

Desta forma, para que estes pontos se concretizem é necessário enfatizar, em um primeiro momento, as diretrizes sob as quais se devem discutir esta relação, trazendo para o âmbito da análise a concepção de perspectiva, bem como sua compreensão em relação ao perfil do profissional que irá dinamizá-la, ação que será levada a cabo baseando-se em Gadotti (2000) e em Müller (1989).

Porém, é preciso considerar, ainda, que as reflexões inscritas no âmbito da sociedade não são elementos desconectados de uma visão de homem, de mundo e de sociedade, razão pela qual optamos por iniciar nossas discussões dialogando com a compreensão de perspectiva conforme formulada por Gadotti (2000), que, ao recuperar a essência etimológica e filosófica do termo, identifica o uso de distintas acepções para o mesmo.

Assim, há a explicitação de que a palavra "perspectiva" vem do latim tardio "perspectivus", que deriva de dois verbos: perspecto, que significa "olhar até o fim, examinar atentamente"; e perspicio, que significa "olhar através, ver bem, olhar atentamente, examinar com

cuidado, reconhecer claramente". Partindo-se desta formulação, Gadotti (2000, p. 3-4) aponta a

partir do Dicionário de filosofia do pensador italiano Nicola Abbagnano, que o termo tem ainda o seguinte significado: "uma antecipação qualquer do futuro: projeto, esperança, ideal, ilusão, utopia".

Há ainda, acrescido a estes sentidos, tal como observado por Gadotti (2000) que perspectiva seria o "aspecto sob o qual uma coisa se apresenta, ponto de vista; expectativa, esperança". Perspectiva significa, portanto e ao mesmo tempo, enfoque, quando se fala, por exemplo, em perspectiva política, e possibilidade, crença em acontecimentos considerados prováveis e bons. "Falar em perspectivas é falar de esperança no futuro". (GADOTTI, 2000, p. 4).

\footnotetext{
${ }^{3}$ Colocação do Prof. Gadotti em exposição oral, no contexto de apresentação de "A função da Universidade: sua realidade e função", PUCCAMP, set. 1981.
} 
Com relação ao perfil profissional, Müeller (1989) propõe que devemos compreendê-lo nos termos abaixo indicados:

O conjunto de conhecimentos, qualidades e competências próprias dos integrantes de uma profissão. O conceito assim entendido está intimamente ligado à idéia de função profissional - o perfil é delineado pelas habilidades, competências e atitudes necessárias para o desempenho da função profissional. (MÜELLER, 1989, p. 63).

Assim, considerando-se os conceitos aqui em foco, torna-se relevante pensarmos que para haver avanço nas relações biblioteca e educação é imprescindível que se combine os aspectos concernentes à perspectiva, na sua vertente de utopia, e os elementos constitutivos do perfil profissional. É necessário, ainda, acrescentar que à combinação perspectiva-perfil deve-se agregar a dimensão de compromisso profissional nos termos propostos por Freire (1986), uma vez que para ele, a designação "compromisso profissional" não se refere a uma abstração, haja vista que o mesmo requer a decisão lúcida e profunda de quem o assume.

Assim, de acordo com a análise de Freire (1986), o homem só se torna capaz de comprometer-se quando atua como sujeito que compreende sua historicidade e o seu estar no mundo de forma concreta. Compreensão que deve ser amplamente mediada pela reflexão e pela ação. Enfatizando esta posição, vale destacar as formulações do autor, conforme indicado a seguir:

Somente um ser que é capaz de sair do seu contexto, de "distanciar-se" dele para ficar com ele; capaz de admirá-lo para, objetivando-o, transformá-lo e, transformando-o, saberse transformado pela sua própria criação: um ser que é e está sendo no tempo que é seu, um ser histórico, somente este é capaz, por tudo isto, de comprometer-se. (FREIRE, 1986, p. 17).

Prosseguindo, vale ainda destacar a ênfase dada pelo autor à necessidade de o profissional não se deixar seduzir pelas técnicas que o escravizam e a importância de exercer de forma crítica a leitura da realidade. Sob tal prisma Paulo Freire destaca:

Quanto mais me capacito como profissional, quanto mais sistematizo minhas experiências, quanto mais me utilizo do patrimônio cultural, que é patrimônio de todos e ao qual todos devem servir, mais aumenta minha responsabilidade com os homens. Não posso, por isso mesmo, burocratizar meu compromisso de profissional, servindo, numa inversão dolosa de valores, mais aos meios que ao fim do homem. (FREIRE, 1986, p. 20). 
Assim, segundo a ótica freiriana, o comprometer-se não é um ato de passividade uma vez que requer, aliado ao conhecimento da realidade, as dimensões de ação e reflexão; sendo assim, para fazê-lo, torna-se imprescindível uma escolha, que é política. Para fazê-lo, torna-se imprescindível uma escolha, que é política. Portanto, defendemos aqui que são estes, em síntese, os elementos que devemos incorporar a fim de que a dimensão de ação se efetive. ${ }^{4}$

\section{Interação Biblioteca-Educação: perspectivas e potencialidades}

De acordo com os elementos explicitados anteriormente torna-se relevante discutir a interação entre biblioteca e educação, uma vez que se compreende que esta interação não só, beneficiaria as áreas envolvidas como, em termos globais, se constituiria em um importante subsídio para o processo educacional.

Em função disso, defende-se que esta interação deve ter como diretriz o conceito de perspectiva, notadamente em seu significado de utopia e esperança, bem como a dimensão de perfil na qual se destacam competências, habilidades e atitudes, mas, também a relevância e significado do compromisso profissional.

Assim, os aspectos citados acima devem se fazer presentes nas duas categorias de profissionais, pois tanto no trabalho do bibliotecário quanto no do educador há a dimensão informacional, estando os mesmos realizando, de forma similar, as funções educativas, marcadas, porém, pelas especificidades e singularidades de cada campo profissional.

Vale ainda destacar que a função educativa e a função informacional não se encontram dissociadas, uma vez que as mesmas se realizam de forma simultânea no fazer destes profissionais. Em razão desta interconexão é necessário que os agentes envolvidos compreendam que os elementos que os integram não se definem pela instituição de vinculação, mas em decorrência da função educativa que exercem.

Em termos concretos é possível apontar que há uma intrínseca relação de integração e complementaridade no fazer de ambos que os transcendem e cuja mediação se efetiva a partir do processo educacional.

Acrescentando aos pontos acima indicados, vale enfatizar que o bibliotecário, mesmo tendo uma formação que o coloca de forma precípua centrado no domínio das técnicas e reconhecendo a importância e a legitimidade das mesmas, o seu fazer profissional requer a interiorização e o domínio de saberes além da técnica, haja vista que a relação se faz com - conhecimento, com sua organização e disseminação e com as potencialidades deste para a leitura e a mudança da realidade históricosocial.

Entretanto, é preciso também chamar atenção para o fato de que competências ocupacionais não são elementos mágicos, mas construções

\footnotetext{
${ }^{4}$ Os argumentos que enfatizam a necessidade de escolha política e ocupação dos espaços, além dos seus limites físicos, têm como base a exposição oral de Paulo Freire em "A função da Universidade" (LOPES; FREIRE; CHAUÍ, 1981).
} 
históricas, razão pela qual aqueles que as exercem devem estar continuamente desenvolvendo e aprimorando seu fazer profissional. Nos termos acima apontados, deve-se privilegiar não só esperança/perspectiva, mas a compreensão política de seu trabalho.

Se os aspectos acima indicados são centrais para o papel educativo do bibliotecário, é necessário também refletir quais as incorporações se tornam necessárias para que o educador, ao efetivar seu trabalho, contribua para a ação informacional.

Desta forma, se a função educativa do bibliotecário tem como centralidade os processos relativos à organização, o tratamento, a disseminação e o acesso à informação, tais procedimentos devem se conectar com a atividade docente, haja vista que os conteúdos que são repassados aos educandos, pela ação do professor, constituem-se como produtos dos saberes acumulados pelo homem ao longo de sua história e que, através do fazer bibliotecário se torna possível recuperar e acessar.

Portanto, percebe-se uma intrínseca relação educativa na função dos profissionais (bibliotecários e educadores) à medida que a ação dos mesmos permite a efetividade da construção do conhecimento. Além disso, ao disponibilizarem história-memória, viabilizam a leitura das diferentes visões da realidade, fazendo emergir as potencialidades de questionar e propor mudanças no contexto histórico-social. Nestes termos e de forma concreta os papéis de bibliotecário e de educador não se antagonizam, uma vez que cada qual, no exercício de suas funções, tem como fundamento a dimensão informacional e em termos intrínsecos atuam como agentes no processo de construção do conhecimento.

Vale acrescentar, ainda, que não há um Bibliotecário e um Educador formados e encaixados em modelos uniformes e estanques, mas profissionais que devem se colocar em permanente construção, à medida que a tarefa educativa os transcende e a efetividade da mesma requer a contribuição dos saberes, competências, habilidades e compromissos de cada um.

\section{A relação biblioteca-educação: paradoxos, limites e avanços}

A partir das discussões até aqui efetuadas fica evidente a importância da interação biblioteca-educação para o processo pedagógico e de suas potencialidades para a educação em âmbito nacional. Entretanto, permanece, de forma paradoxal, uma contraposição entre a dimensão do discurso e a realidade, tendo em vista que, no plano do ideal, advoga-se a necessidade da interlocução entre bibliotecários e educadores, dos benefícios e avanços que podem advir desta interação e da indissociabilidade entre biblioteca e educação como faces da mesma moeda.

Porém, ao se analisar as dificuldades anteriormente indicadas, deparamo-nos com as limitações impostas pela ausência de interlocução entre as áreas, pelas limitações de uma formação que não privilegia a dimensão educativa do fazer bibliotecário e que também não incorpora no 
contexto da formação do educador, a interiorização da biblioteca como um espaço importante para os distintos sujeitos inscritos no contexto educativo.

Em razão dos aspectos acima indicados, é possível dizer que tais limitações terminam por produzir uma visão equivocada por parte dos bibliotecários e dos educadores em relação ao real significado de seus papéis, razão pela qual ambos se colocam fechados nos espaços considerados legítimos - a biblioteca e a sala de aula - mantendo-se, assim, a separação entre os processos de atuação, o que, em última instância, legitima uma atitude conservadora das instituições.

Deve-se, ainda, esclarecer que estas contradições e limites não se constituem em um absoluto, motivo pelo qual é possível pensar em formas para se avançar e romper com tais restrições, além de apontar mudanças possíveis e colocar em perspectiva alguns aspectos que podem se constituir como caminhos de intervenção na realidade da biblioteca e da educação.

No que se refere ao âmbito de ação da biblioteca, Silveira (2007) propõe que esta, enquanto uma instituição pública e/ou privada deve realizar as seguintes funções: cultural, informacional, recreativa e educacional.

Assim, considerando-se estas funções, torna-se oportuno que o bibliotecário, no contexto de suas ações, enfatize os seguintes aspectos:

- Possibilitar que as diferentes vertentes culturais da realidade brasileira se tornem presentes, permitindo a interlocução entre acervo, memória e cultura;

- Incentivar e tornar factível que os representantes dos diferentes espaços sociais tenham acolhida e acesso às potencialidades da informação hoje disponibilizadas;

- Permitir que em sua vertente recreativa os usuários vivenciem as dimensões lúdicas e críticas propiciadas pelas atividades de ação cultural, bem como pela diversidade dos materiais hoje incorporados aos acervos;

- Desenvolver atividades de discussão e aprofundamento das temáticas curriculares, privilegiadas na ação educativa e que se encontram presentes no âmbito do processo pedagógico.

Quanto à atuação docente, é imprescindível buscar sua efetividade através das seguintes ações:

- Estabelecer ações de parceria entre bibliotecários e educadores de forma que as propostas relativas à construção do conhecimento utilizem, de maneira mais intensiva, os aportes advindos da biblioteca;

- Planejar a construção de processos de aprendizagem a partir do acervo da biblioteca; 
- Promover campanhas educativas de sensibilização, enfatizando a importância da preservação do conhecimento e da memória;

- Ampliar a interlocução entre os processos educativos, considerando os benefícios e avanços que poderão advir desta interação e da indissociabilidade entre biblioteca e educação;

- Atuar conjuntamente com os bibliotecários no sentido de divulgar o acervo e suas potencialidades culturais, visando o desenvolvimento da criatividade e da sensibilidade dos usuários;

- Indicar, no processo de planejamento pedagógico, as dimensões de interação a serem efetivadas a partir do trabalho dos bibliotecários e dos educadores.

Em face destas indicações e das potencialidades que as mesmas carregam, percebe-se que realizá-las é factível, à medida que haja por parte dos profissionais a compreensão de que a manutenção da dicotomia bibliotecários-educadores resulta de um processo histórico, que vem sendo reificado nas práticas cotidianas e decorrem da própria estrutura social brasileira e das condições históricas da educação nacional, as quais é preciso romper.

Portanto, para se realizar a mudança dessa situação é preciso analisar criticamente as contradições da sociedade brasileira e propor uma mudança nas práticas culturais bem como a adoção de um novo posicionamento por parte dos profissionais.

Em síntese, à medida que se apontam alternativas de pensar sobre os aspectos contraditórios que intervêm nos processos de trabalho de bibliotecários e de educadores e ao se compreender que o cerne das atividades destes profissionais são os processos de difusão da informação, de construção do conhecimento e de desenvolvimento da imaginação, os argumentos aqui apresentados nos ajudam a indicar que a interação de bibliotecários e educadores precisa deixar de ser retórica e se realizar como práxis, de forma a contribuir para a transformação da realidade. Portanto, vale refletir sobre luz/esperança, conforme discussão apresentada no tópico a seguir.

\section{Repatriar luz/ esperança}

Em face das considerações formuladas nos tópicos antecedentes, a partir dos quais se destacou a importância da biblioteca e da educação, definimos por incluir também, como dimensão político-ideológica e elemento de ação a ideia de repatriar, tendo em vista seu significado que é utilizado por Ivan Lins, Vitor Martins, Ivano Fosseti, na música "Quero falar de amor", na qual fazem reverberar, no seu refrão, a necessidade de "repatriar a luz para os olhos da mocidade". 
De forma concreta e pensando na práxis ${ }^{5}$ destas instituições, tal conceito entendido como "ação de reciprocidade entre os indivíduos", conforme colocado por Ribeiro (2003), a partir das formulações teóricas de Hannah Arendt, torna-se possível acreditar na viabilidade de ações conjuntas a se efetivar entre a biblioteca e a educação, de forma a atuar de forma dinâmica como instrumentos de luz e esperança.

Assim, nos termos indicados acima, as ações da biblioteca se centrariam no compromisso de socializar a informação, privilegiar os direitos de cidadania e ampliação do acesso à leitura; por sua vez, no que se refere à educação, seu desenvolvimento deveria ter como centralidade a preocupação de garantir, para além da alfabetização, o domínio dos conhecimentos já produzidos pela cultura, de forma que os sujeitos tenham capacidade de se localizarem no mundo e exercerem de forma crítica seu papel de cidadão.

Desta forma, acreditamos que o conceito de repatriar, ao ser traduzido em ação, requer um compromisso permanente de socializar a cultura e os saberes já produzidos pelos homens, tendo como fim precípuo iluminar a visão da juventude em relação ao mundo que o circunda,

de forma que, compreendendo as contradições e dificuldades para os processos de mudança, possam partilhar de uma visão global da realidade que lhes dê fundamento para o efetivo exercício da práxis.

Entretanto, se no plano da reflexão, aventar os aspectos a serem enfatizados para a ação e de suas possibilidades são factíveis de serem propostas, há, porém, dificuldades concretas para sua realização. Em termos reais, conforme Freire e Guimarães (1984, p. 47) discutem, esbarra-se com uma série de limites que os autores colocam nos seguintes termos: "Acho que a falta, [limitação] a muitos de nós, educadores [ ] é a imaginação. A gente tem medo de deixar a imaginação voar, mas é preciso deixá-la voar! Não voar a ponto de se perder, mas voar, imaginar coisas concretas, coisas possíveis, com as crianças" ${ }^{\prime \prime}$ Por outro lado, além da imaginação, precisamos compreender que os processos de mudança da sociedade e das instituições, no caso presente, da biblioteca e da educação, se fazem dialeticamente pelos limites históricos e pelas ações concretas dos homens; tal fato, porém, demanda daqueles que se preocupam com estas limitações agirem de forma cotidiana na ocupação dos espaços e na construção de alternativas que possam romper com o "status quo".

Orientados por tais indagações, vale destacar, como elemento imprescindível à necessidade de meditar sobre as exigências do "repatriar luz para os olhos da juventude", bem como mirar-se no fazer da "Mestra

\footnotetext{
5 Conforme discutido e apontado por Ribeiro (2003), com base em Hannah Arendt, o conceito, em termos históricos, apresenta-se com o sentido "que tem a ação para os gregos, que era a ação recíproca entre os homens, ou práxis", ou seja, a práxis compreende uma ação que privilegia as relações entre os homens; esta visão contrapõe-se a ideia de práxis como ação de "fabricação" própria do contexto moderno e das relações capitalistas de produção nas quais homens e produtos se transformam em objeto.

${ }^{6}$ A formulação de Freire \& Guimarães no que se refere à dimensão da imaginação "imaginar coisas concretas, coisas possíveis com as crianças" decorre do diálogo dos autores- refletindo sobre os desafios da escola básica e em face da realidade das crianças que têm, na escola, sua única oportunidade de aprendizagem e acesso ao saber.
} 
Silvina" lembrada por Cora Coralina, haja vista que num país marcado pelas diferenças sociais e de exclusão, as instituições - bibliotecas e escolas - representam, muitas vezes, para a maioria da população, a única oportunidade de sair da "oclusão".

\section{Conclusões}

Partindo-se dos elementos expostos anteriormente e que, acredito, fazem parte das reflexões de bibliotecários e professores, torna-se oportuno integrar-se, como preocupação dos profissionais, o fato de que em termos científicos, institucionais e pessoal há limitações as quais precisamos romper, a fim de que se torne possível aproximar o real do idealizado.

Vale acrescentar, ainda, que se desejamos avançar, indo além da burocracia de nossas instituições, de forma a vencer os nossos próprios medos e limites devemos reconhecer que atuar na dimensão de Bibliotecário-Educador implica assumir uma posição política - ter clareza com o que estamos comprometidos e a quem desejamos servir - e ocupar este espaço, pois ele só se alargará pelo nosso trabalho e a efetividade de nossas ações. Torna-se necessário, também, assumir um posicionamento centrado na preocupação de buscar, de forma permanente, além da centralidade dada aos usuários, a interlocução nas diferentes instâncias pedagógicas - diretores, orientadores pedagógicos e docentes - de forma a aproveitar brechas e estabelecer parcerias visando o processo de mudança nas práticas culturais, facultando, assim, que a biblioteca ocupe no processo pedagógico a centralidade que lhe é inerente.

Porém, se os aspectos acima indicados são centrais para o papel educativo do bibliotecário, torna-se necessário refletir quais as incorporações devem ser pensadas para que o educador exerça, nessa relação de interação, uma atuação que poderíamos nomear como a de um Educador-Bibliotecário.

Sob tal prisma o que se requer é que haja uma aproximação efetiva do educador com o espaço da biblioteca, apreendendo-a não como espaço físico, mas como lócus dinâmico de construção do conhecimento. Para tal, é imprescindível que haja, no contexto da experiência pedagógica, a apropriação das diferentes possibilidades do acervo e dos desafios que neles se encontram inseridos, assim como uma visão alargada das potencialidades de diferentes e contraditórios diálogos que se fazem presente na biblioteca, aspectos que permitem compreender a realidade sob uma ótica plural.

Ressalvo, porém, que não há receitas prontas e mágicas e que o desafio é o de estar aberto à mudança e com disposição de correr riscos. Uma difícil tarefa aguarda a todos, com limitações em maior ou menor escala em cada espaço institucional. Portanto, é necessário tornar concreto estes desafios, de forma a consolidar os elos que aproximam a tríade informação, conhecimento e imaginação. Para fazê-lo é fundamental romper com a situação paradoxal que ainda hoje se faz 
presente nas relações sociais e institucionais e unirmos para darmos os primeiros passos.

Referências

ALMEIDA, M. C. B. de. Ação cultural do bibliotecário: grandeza de um papel e limitações da prática. Revista Brasileira de Biblioteconomia e Documentação. São Paulo, v. 20, n. 1, p. 31-38, jan./dez. 1987.

BENEVIDES, Maria Victoria de Mesquita. Educação para a democracia. Lua Nova: Revista de Cultura e Política, n. 38, p. 223-235, dez. 1996.

BRANDÃO, Carlos Rodrigues. O que é educação. 12. ed. São Paulo: Brasiliense, 1984. 116p.

CABRAL, Ana Maria Rezende. Ação cultural: possibilidades de atuação do bibliotecário. In: VIANNA, Márcia Milton; CAMPELLO, Bernadete; MOURA, Victor Hugo Vieira. Biblioteca escolar: espaço de ação pedagógica. Belo Horizonte: EB/UFMG, 1999. p. 39-45.

CARVALHO, José Murilo de. Cidadania no Brasil: o longo caminho. Ed. Civilização Brasileira, 2010.

CURY, Carlos Roberto Jamil. A educação como desafio na ordem jurídica. In: LOPES, Eliane Marta Teixeira et al. (Org.). 500 anos de educação no Brasil. 3. ed. Belo Horizonte: Autêntica, 2007. p. 567-584.

DELORS, Jaques. Educação: um tesouro a descobrir. Brasília: Cortez, 1996.

DOURADO, Luiz Fernandes. Políticas e gestão da educação básica no Brasil: limites e perspectivas. Educação \& Sociedade, Campinas, v. 28, n. 100, p. 921-946, especial out. 2007.

DUPAS, Gilberto. Economia global e exclusão social: pobreza, emprego, Estado e o futuro do capitalismo. 2. ed. rev. e ampl. São Paulo, Paz e Terra, 1999.

FLUSSER, Victor. A biblioteca como um instrumento de ação cultural. Revista da Escola de Biblioteconomia da Universidade Federal de Minas Gerais, v. 12, n. 2, p. 139-284, set. 1983.

FLUSSER, Victor. Uma biblioteca verdadeiramente pública. Revista da Escola de Biblioteconomia da UFMG, Belo Horizonte, v. 9, n. 2, p. 131138 , set. 1980.

FREIRE, Paulo. O compromisso do profissional com a sociedade. In: FREIRE, Paulo. Educação e mudança. 11. ed. Rio de Janeiro: Paz e Terra, 1986. p. 15-25.

FREIRE, Paulo; GUIMARÃES, Sérgio. Sobre educação: diálogos. Rio de Janeiro: Paz e Terra, 1984. v. 2.

FREITAG, Bárbara. Escola, estado e sociedade. 7. ed. rev. São Paulo: Centauro, 2005. 
GADOTTI, Moacir. Perspectivas atuais da educação. São Paulo em Perspectiva, São Paulo, v. 14, n. 2, p. 3-11, 2000.

LOPES, Gilberto Pereira; FREIRE, Paulo; CHAUÍ, Marilena. A função da Universidade, sua realidade e função. In: SEMINÁRIO PUC CAMPINAS, 16 set. 1981.

LOURENÇO FILHO. M. B. O ensino e a biblioteca: $1^{\text {a }}$ Conferência da série educação e biblioteca. Rio de Janeiro. Imprensa Nacional, 1994.

MACHADO, Elisa Campos. Análise de políticas públicas para bibliotecas no Brasil. InCID: Revista de Ciência da Informação e Documentação, Ribeiro Preto, v. 1, n. 1, p. 94-111, 2010.

MÜELLER, Suzana Pinheiro Machado. Perfil do bibliotecário, serviços e responsabilidades na área de informação e formação profissional. Revista de Biblioteconomia de Brasília, Brasília, v. 17, n. 1, p. 63-70, jan./jun. 1989.

MÜLLER, Suzana Pinheiro Machado. Biblioteca e sociedade: evolução da interpretação das funções e papéis da biblioteca. Revista da Escola de Biblioteconomia da UFMG, Belo Horizonte, v. 13, n. 1, 7-54, mar. 1984.

REIS, Alcenir Soares dos; MARTINS, Ana Amélia Lage. Movimentos sociais, informação e mediação: uma visão dialética das negociações de sentido e poder. DataGramaZero - Revista de Ciência da Informação, v. 10, n. 5, out. 2009. Disponível em: <http://dgz.org.br/out09/F_I_art.htm>. Acesso em: 07 dez. 2009.

RIBEIRO, Renato Janine. Da natureza à cultura. In: NOVAES, Adauto. $O$ homem máquina: a ciência manipula o corpo. Companhia das Letras, 2003.

SILVEIRA, Fabrício José Nascimento da. Biblioteca como lugar de práticas culturais: uma discussão a partir dos currículos de Biblioteconomia no Brasil. 2007. 246f. Dissertação (Mestrado em Ciência da Informação)Escola de Ciência da Informação da Universidade Federal de Minas Gerais, Belo Horizonte, 2007.

SILVEIRA, Fabrício José Nascimento da. O bibliotecário como agente histórico: do "humanista ao "Moderno Profissional da Informação". Informação \& Sociedade: Estudos, João Pessoa, v. 18, n. 3, p. 83-94, set./dez. 2008.

SILVEIRA, Fabrício Jose Nascimento da; REIS, Alcenir Soares dos. Biblioteca como lugar de práticas culturais: uma discussão sócio-histórica. Informação \& Sociedade: Estudos, v. 21, n. 1, p. 37-54, jan./abr. 2011.

TOURAINE, Alain; Um novo paradigma: para compreender o mundo de hoje. Tradução de Gentil Avelino Titton. Petrópolis: Vozes, 2006. 261p.

VILELA, Raquel Miranda. Biblioteca escolar e EJA: caminhos e descaminhos. 2009. 141f. Dissertação (Mestrado em Ciência da Informação)-Escola de Ciência da Informação da Universidade Federal de Minas Gerais, Belo Horizonte, 2009. 
